\title{
BMJ Open Cohort profile: LIFEWORK, a prospective cohort study on occupational and environmental risk factors and health in the Netherlands
}

\author{
Marije Reedijk, ${ }^{1,2}$ Virissa Lenters, ${ }^{1}$ Pauline Slottje, ${ }^{1,3}$ Anouk Pijpe, ${ }^{4}$ \\ Petra H Peeters, ${ }^{2,5}$ Joke C Korevaar, ${ }^{6}$ Bas Bueno-de-Mesquita, ${ }^{5,7}$ \\ W M Monique Verschuren, ${ }^{2,7}$ Robert A Verheij, ${ }^{6}$ Inka Pieterson, ${ }^{1}$ \\ Flora E van Leeuwen, ${ }^{4}$ Matti A Rookus, ${ }^{4}$ Hans Kromhout, ${ }^{1}$ Roel C H Vermeulen ${ }^{1,2,5}$
}

To cite: Reedijk M, Lenters V, Slottje P, et al. Cohort profile: LIFEWORK, a prospective cohort study on occupational and environmental risk factors and health in the Netherlands. BMJ Open 2018;8:e018504. doi:10.1136/ bmjopen-2017-018504

- Prepublication history and additional material for this paper are available online. To view these files, please visit the journal online (http://dx.doi. org/10.1136/bmjopen-2017018504).

PS and AP contributed equally, MAR, HK and RCHV contributed equally,

$M R$ and VL contributed equally.

Received 4 July 2017

Revised 1 December 2017

Accepted 4 December 2017

Check for updates

For numbered affiliations see end of article.

Correspondence to

Roel C H Vermeulen;

r.c.h.vermeulen@uu.nl

\section{ABSTRACT}

Purpose LIFEWORK is a large federated prospective cohort established in the Netherlands to quantify the health effects of occupational and environmental exposures. This cohort is also the Dutch contribution to the international Cohort Study of Mobile Phone Use and Health (COSMOS). In this paper, we describe the study design, ongoing data collection, baseline characteristics of participants and the repeatability of key questionnaire items.

Participants 88466 participants were enrolled in three cohort studies in 2011-2012. Exposure information was collected by a harmonised core questionnaire, or modelled based on occupational and residential histories; domains include air pollution (eg, nitrogen dioxide $\left(\mathrm{NO}_{2}\right)$, particulate matter with diameter $\left.\leq 2.5 \mu \mathrm{m}\left(\mathrm{PM}_{2.5}\right)\right)$, noise, electromagnetic fields (EMF), mobile phone use, shift work and occupational chemical exposures. Chronic and subacute health outcomes are assessed by self-report and through linkage with health registries.

Findings to date Participants had a median age of 51 years at baseline (range 19-87), and the majority are female (90\%), with nurses being over-represented. Median exposure levels of $\mathrm{NO}_{2}, \mathrm{PM}_{2.5}$, EMF from base stations and noise at the participants' home addresses at baseline were $22.9 \mu \mathrm{g} / \mathrm{m}^{3}, 16.6 \mu \mathrm{g} /$ $\mathrm{m}^{3}, 0.003 \mathrm{mWm}^{2}$ and $53.1 \mathrm{~dB}$, respectively. Twentytwo per cent of participants reported to have started using a mobile phone more than 10 years prior to baseline. Repeatability for self-reported exposures was moderate to high (weighted kappa range: 0.69-1) for a subset of participants $(n=237)$ who completed the questionnaire twice.

Future plans We are actively and passively observing participants; we plan to administer a follow-up questionnaire every 4-5 years-the first follow-up will be completed in 2018-and linkage to cause-of-death and cancer registries occurs on a (bi)annual basis. This prospective cohort offers a unique, large and rich resource for research on contemporary occupational and environmental health risks and will contribute to the large international COSMOS study on mobile phone use and health.

\section{Strengths and limitations of this study}

- Occupational and environmental circumstances and exposures are constantly changing over time; contemporary prospective cohorts are necessary to address potential health effects of new and emerging exposures.

- LIFEWORK is a contemporary federated prospective cohort in the Netherlands that periodically collects a large amount of data on lifetime occupational and environmental circumstances to characterise timevarying exposure patterns as well as symptoms and chronic health outcomes over time for nearly 90000 participants

- A large proportion of the cohort consists of women $(90 \%)$ who are over the age of 50 years $(54 \%)$, with an over-representation of nurses $(66 \%)$ due to the design of the cohort.

- The large sample size, widespread geographical coverage across the Netherlands and large contrast in exposure levels allow for the investigation of both common and relatively rare diseases.

- As LIFEWORK is designed to assess lifetime occupational and environmental risk factors, it is well positioned to have an important contribution to exposome research.

\section{INTRODUCTION}

People are exposed to a myriad of occupational and environmental circumstances throughout their lifetime. Some exposures, such as air pollution, are well-established risk factors for acute and chronic disease outcomes; for others, like electromagnetic fields (EMF), uncertainty remains about their effects on health. ${ }^{2}$ Until now the majority of research has evaluated health effects of single exposures, while occupational and environmental exposures often occur in complex mixtures (either simultaneous and/or intermittent) and at low concentrations. ${ }^{3} 4$ Therefore, to 
obtain more accurate exposure-health effect estimates, it is important to assess the effects of multiple simultaneous exposures on different health outcomes during the entire life course by using state-of-the-art exposure assessment tools and information. ${ }^{5}$ This has recently been formalised in the exposome concept, which proposes to study the totality of environmental exposures over the life course. ${ }^{6}$

Although the health effects of environmental exposures are frequently small in magnitude, the disease burden is potentially large, as the prevalence of many exposures is high. The Global Burden of Disease study estimated that about half of global deaths are attributable to modifiable exposures such as particulate air pollution (both household and ambient), smoking, physical activity and diet. ${ }^{7}$ Nevertheless, a large proportion of disease caused by modifiable factors remains unexplained. ${ }^{89}$ Although a couple of large occupational and environmental cohorts have recently been established, such as CONSTANCES, ${ }^{10}$ occupational and environmental risk factors for health have generally been studied either in narrowly focused, mainly retrospective studies, or more broadly as an additional topic in ongoing cohort studies which initially had another focus.

Therefore, we established a large prospective cohort study, LIFEWORK, comprising three cohorts, with a focus on comprehensively assessing occupational and environmental exposures, and health. ${ }^{11-13}$ We gathered information on participants' complete residential and occupational histories in an effort to capture changes in important aspects of the external exposome throughout the life course, and also gathered information on (sub)acute and chronic health outcome data. This cohort also contributes to the six-country effort to investigate the potential health effects of long-term use of mobile phones (the Cohort Study of Mobile Phone Use and Health $\left.(\mathrm{COSMOS})^{14}\right)$. Both self-reported and operator-recorded mobile phone use data are collected over time, allowing for improved exposure assessment. ${ }^{15}$ Another area of interest is how health is affected by communication technologies (eg, blue light) and shift work, which drive the modern 24 hours' economy.

Our study was designed to assess a broad array of environmental and occupational exposures, with a focus on mobile phone use and exposure to EMF. In this paper, we present the LIFEWORK cohort by describing the study design, data collection, baseline characteristics, exposure distributions, the repeatability of several key questionnaire items and projected study power for several outcomes.

\section{COHORT DESCRIPTION}

\section{Study design and procedures}

The prospective LIFEWORK cohort was established to collect a large amount of high-quality data on occupational and environmental exposures using a harmonised core questionnaire. To achieve a large study population, data collection was integrated into an already existing cohort (EPIC-NL, the European Prospective Investigation into Cancer and Nutrition in the Netherlands) and two de novo cohorts (the Nightingale Study and AMIGO, the Occupational and Environmental Health Cohort Study). From the outset, the LIFEWORK cohort was designed as a federated study, where the subcohorts are governed by an overarching governance board alongside independent governance boards, and data collection was designed to capture a core set of exposures and outcomes of interest. In addition to the harmonised core data collected on exposures and health outcomes, each of these cohorts collected data to fulfil additional research aims (described in the Data collection section). Deviations in data collection across the three subcohorts are briefly described below and are detailed in online supplementary table S1, including which data required harmonisation.

Study designs and recruitment for the individual cohorts have previously been described. ${ }^{11-13}$ Briefly, the LIFEWORK cohort comprises: (1) female (current and former) nurses, aged 18-65 years at enrolment in 2011, who were recruited via the registration system for healthcare professionals, that is, the BIG-register (the Nightingale Study $)^{13}$; (2) adults from the general population, aged 31-65 years at recruitment in 2011-2012, who were recruited, with a maximum of one person per household, via a national general practitioners network, that is, the NIVEL Primary Care Database (AMIGO) ${ }^{12}$; and (3) participants from the EPIC-NL cohort. EPIC-NL participants were originally recruited between 1993 and 1997 ( $n=40$ 011), either via a breast cancer screening programme conducted in Utrecht and neighbouring towns (women aged 49-70 years; EPIC-NL Prospect), or from the general population of three cities, Amsterdam, Doetinchem and Maastricht (adults aged 20-59 years; EPIC-NL MORGEN; participants from Doetinchem were not invited for LIFEWORK). ${ }^{11}$ The LIFEWORK baseline questionnaire was the baseline questionnaire for AMIGO and Nightingale (2011-2012) and the third questionnaire for EPIC-NL (2011). Participants signed an informed consent form for each subcohort prior to enrolment.

A total of 88731 participants (of whom 88466 are unique) were enrolled in 2011 and 2012 upon completion of a self-administered paper questionnaire (EPIC$\mathrm{NL}$ ) or web-based questionnaire (with the option to receive a paper version; Nightingale and AMIGO). With 59941 participants $(67 \%)$, the Nightingale Study is the largest cohort contributing to LIFEWORK, followed by AMIGO (n=14 829, 17\%) and EPIC-NL ( $\mathrm{n}=13$ 961, 16\%). The participation rates were $16 \%$ for AMIGO, $31 \%$ for Nightingale and $51 \%$ for EPIC-NL (response in 20112012, the third follow-up; and $40 \%$ at EPIC-NL baseline in 1993-1997). Compared with the 40011 who enrolled at EPIC-NL baseline (1993-1997), the 13961 EPIC-NL study participants who participated in LIFEWORK (ie, responded to the third EPIC-NL questionnaire in 2011/2012) had a similar age distribution (mean age of 50 vs 49 years), and a greater proportion were higher educated (28\% vs $20 \%)$ and were women $(80 \%$ vs $74 \%)$. 
Table 1 Key topics in the LIFEWORK baseline questionnaire and the models used to assess environmental and occupational exposures

\section{Questionnaire}

\begin{tabular}{ll}
\hline Topic & Items \\
\hline Characteristics & Age, sex, marital status, country of birth, height, weight \\
\hline Socioeconomic & Employment status, education \\
\hline Lifestyle & Smoking, alcohol use, physical activity \\
\hline Housing characteristics & Bedroom floor, position of the bedroom relative to the street \\
\hline Residential history & Full residential history of addresses lived at for at least 12 months \\
\hline Occupational history & $\begin{array}{l}\text { AMIGO/EPIC-NL: full history of jobs performed for at least } 6 \text { months (job title, type of company, } \\
\text { average number of hours per week), shift work (ever shift work and if permanent or rotating shift } \\
\text { system) }\end{array}$ \\
& $\begin{array}{l}\text { The Nightingale Study: full history of jobs performed for at least } 6 \text { months (job title, type of } \\
\text { company, average number of hours per week, shift work, physical activity), shift work (rotation, } \\
\text { frequency, calendar years), chronotype (MEQ) }{ }^{60 *}\end{array}$ \\
& $\begin{array}{l}\text { Current and historical mobile phone use, cordless phone use and internet mobile phone uset, job } \\
\text { tasks or use of equipment likely to lead to high EMF exposure }\end{array}$ \\
\hline EMF exposure & $\begin{array}{l}\text { Current: physical and mental well-being (SF-12), headache (HIT-6), }{ }^{16} \text { migraine (ID-migraine), }{ }^{17} \\
\text { sleep quality (MOS sleep scale), }{ }^{18} \text { memory problems, hearing problems, tinnitus } \\
\text { Past: doctor-assessed symptoms and diseases, and age at diagnosis for conditions and events } \\
\text { including diabetes, cardiovascular events, neurodegenerative diseases, cancer, asthma* }\end{array}$ \\
& Reproductive health (women): parity, birth outcomes, hormone use ${ }^{*}$
\end{tabular}

\begin{tabular}{|c|c|}
\hline Modelled exposures & \\
\hline Geospatial model & Environmental exposures \\
\hline NISMap 2324 & RF-EMF from mobile phone base stations \\
\hline ESCAPE LUR model ${ }^{26} 27$ & Air pollutants $\left(\mathrm{PM}_{2.5}, \mathrm{PM}_{2.5}\right.$ absorbance, $\left.\mathrm{PM}_{10}, \mathrm{NO}_{2}, \mathrm{OP}_{\mathrm{dtt}}\right)$ \\
\hline$N D V I^{25}$ & Green space measure \\
\hline STAMINA ${ }^{28}$ & Traffic noise exposure (eg, $\left.\mathrm{L}_{\text {den }}\right)$ \\
\hline LOCATUS 29 & Built environment (eg, number of fast food restaurants and sport facilities in surrounding area) \\
\hline Job-exposure matrix & Occupational exposures \\
\hline ALOHA+JEM ${ }^{32} 33$ & $\begin{array}{l}\text { Dust (biological, mineral dust), pesticides (all pesticides, herbicides, insecticides, fungicides), } \\
\text { solvents (total solvents, aromatic solvents, chlorinated solvents) }\end{array}$ \\
\hline DOM-JEM 3435 & $\begin{array}{l}\text { Diesel motor exhaust fumes, asbestos, chromium, nickel, PAHs, silica, animal dust, biological } \\
\text { dust, endotoxin }\end{array}$ \\
\hline Shock-JEM ${ }^{36}$ & Electric shocks at work \\
\hline ELF-MF JEM ${ }^{61}$ & Extremely low-frequency magnetic fields \\
\hline
\end{tabular}

*Items differed slightly between AMIGO, EPIC-NL and the Nightingale questionnaires; more detailed information can be found in online supplementary table S1.

†More detailed information can be found in Schüz et al..$^{14}$

AMIGO, Occupational and Environmental Health Cohort Study; ELF-MF, extremely low-frequency magnetic fields; EMF, electromagnetic fields; EPIC-NL, European Prospective Investigation into Cancer and Nutrition in the Netherlands; ESCAPE, European Study of Cohorts for Air Pollution Effects; HIT, Headache Impact Test; ID-migraine, identification of migraine; JEM, job-exposure matrix; $L_{d e n}$, day-evening-night weighted average traffic noise level for 2011; LUR, land use regression; MEQ, Morningness-Eveningness Questionnaire; MOS, Medical Outcomes Study; NDVI, Normalized Difference Vegetation Index; $\mathrm{NO}_{2}$, nitrogen dioxide; $\mathrm{OP}_{\mathrm{dtt}}$, oxidative potential; $\mathrm{PAH}$, polycyclic aromatic hydrocarbon; $\mathrm{PM}_{10}$, particulate matter with diameter $\leq 10 \mu \mathrm{m}$; RF-EMF, radiofrequency electromagnetic fields; SF, Short Form Health Survey; STAMINA, Standard Model Instrumentation for Noise Assessments.

Participants were asked to consent to linkage to the Municipal Personal Records Database and health registries (eg, cancer and mortality). Consent was a prerequisite for participation in AMIGO and Nightingale and was therefore $100 \%$. In EPIC-NL, consent for linkage was obtained for $97 \%$ at baseline (19931997). ${ }^{11}$ Participants were also asked at enrolment (2011-2012) to consent to linkage to their mobile phone operators to obtain data on their monthly mobile phone use, although it was clearly stated that this was optional and not a prerequisite for participation. Up to 35966 participants (41\%) consented to this.

\section{Duplicate enrolments}

Participants were independently invited to participate in the three cohort studies, and the source populations 
overlapped somewhat. It was therefore possible that participants enrolled in more than one subcohort, and received the LIFEWORK baseline questionnaire more than once. Up to 265 participants completed more than one LIFEWORK questionnaire (15 both AMIGO and EPIC-NL, 184 both AMIGO and Nightingale and 66 both Nightingale and EPIC-NL).

\section{Data collection}

Questionnaire data

Topics included in the LIFEWORK baseline questionnaire are listed in table 1 and elaborated in online supplementary table S1. Information on mobile phone use and other wireless technologies was assessed according to the COSMOS protocol. ${ }^{14}$ Validated questionnaires were used to assess various health outcomes, many of which were also included in COSMOS. ${ }^{16-20}$ Occupational EMF exposures were assessed considering sources (eg, MRI equipment and dielectric heating) with high EMF exposure levels. Information on an extensive set of potential confounders, including sociodemographic, socioeconomic and lifestyle factors was collected, along with information on important modifiers of exposure and coexposures.

In addition to the core LIFEWORK data, each subcohort had additional research aims and collected more extensive information on dedicated topics. In the Nightingale Study, this included shift work and more established hormone-related cancer risk factors, including reproductive factors. ${ }^{17}$ EPIC-NL was initiated to study the relationship between nutrition and cancer, and later the focus of the questionnaires broadened to study the aetiology of other major chronic diseases and reproductive health. ${ }^{11}$ The AMIGO questionnaire incorporated additional questions on self-reported health (eg, respiratory health and somatisation symptoms), indoor exposures and risk perceptions and concerns about environmental exposures. ${ }^{12}{ }^{21}$ A LIFEWORK follow-up questionnaire campaign is expected to be complete in 2018: it was administered for the EPIC-NL and AMIGO subcohorts from April to November 2015, and for the Nightingale subcohort starting in July 2017 and is expected to be completed in 2018. The contents of the follow-up questionnaire are described in online supplementary table S1. The intention is to continue to collect questionnaire data every $4-5$ years, contingent on funding.

\section{Exposure assessment}

Detailed information was collected on occupational and residential histories, which allows for estimation of life course residential and occupational exposures. The various geospatial environmental exposure models and job-exposure matrices (JEMs) that have thus far been applied are listed in table 1 .

So far, several environmental exposures have been modelled for the baseline geocoded ${ }^{22}$ home addresses. For example, radiofrequency (RF)-EMF from mobile phone base stations at the reported bedroom floor, where people spend the most time while at home, were estimated for each participant using the three-dimensional radio wave propagation model, NISMap. ${ }^{23}{ }^{24} \mathrm{~A}$ measure of greenness in a $1000 \mathrm{~m}$ buffer around the home was assigned by calculating the mean of the Normalized Difference Vegetation Index (NDVI) for 2011. The NDVI is the difference between red and near-infrared radiation, ranging from -1 to +1 , where low values reflect low vegetation (eg, water) and high values reflect high vegetation. ${ }^{25}$ Ambient air pollution estimates (nitrogen dioxide $\left(\mathrm{NO}_{2}\right)$, particulate matter with an aerodynamic diameter $\leq 2.5$ and $\leq 10 \mu \mathrm{m}$ $\left(\mathrm{PM}_{2.5}\right.$ and $\left.\mathrm{PM}_{10}\right), \mathrm{PM}_{2.5}$ absorbance (a marker of black carbon) and oxidative potential of $\mathrm{PM}_{2.5}$ ) were derived using the land use regression models developed for the European Study of Cohorts for Air Pollution Effects for the years 2008-2011. ${ }^{26} 27$ The models incorporate air pollution monitoring network, land use and traffic count data. Exposure from road traffic noise was estimated with the Standard Model Instrumentation for Noise Assessments ${ }^{28}$; this model incorporates data on traffic intensities, speed, composition, type of road surface, building data and ground type. Twenty-fourhours weighted average road traffic noise $\left(\mathrm{L}_{\mathrm{den}}\right)$ levels, with penalties for the evening and night-time periods, were estimated at the home addresses. ${ }^{28}$ Estimates of PM element composition, including trace elements, and aspects of the built environment (eg, number of nearby fast food restaurants and sports facilities) will also be modelled. ${ }^{29} 30$

Occupational exposures can be assigned based on the self-reported occupational histories, and linked to JEMs. JEMs are cross-tabulations of exposure scores and job titles that are used to assign quantitative or qualitative occupational exposure levels. As (expert-based) classification of job titles is a time-consuming exercise, we decided to code a random subset allowing for more rapid implementation of the efficient case-cohort study design, as previously applied. ${ }^{31}$ As of 2016 , job histories prior to baseline (2011/2012) have been coded using the International Standard Classification of Occupations (ISCO-88) classification system for a random subset of 4961 participants. The job-specific codes have until now been linked to the ALOHA+JEM, DOM-JEM and shock-JEM to estimate lifetime exposure to numerous chemical, physical and biological agents, as described in table $1 .^{32-37}$ Within the aforementioned JEMs, limited distinction is made for the different nursing occupations or job tasks, as the ISCO-88 coding scheme has only a few specific codes for nursing jobs. Therefore, additional questions regarding specific occupational exposures were asked in the Nightingale questionnaire for nurses (eg, contact with antineoplastic drugs, antibiotics).

As part of the COSMOS study, in addition to self-reported data, information on mobile phone use is obtained from mobile phone network operators for the participants who consented. ${ }^{14}$ Operator data include the monthly number and duration of calls, and number of short message service text messages. Operator data are continuously available from 3 months prior to the baseline questionnaire; so the collection period for operator 
and self-reported data overlaps. Operator data were only obtained for $\sim 50 \%$ of participants who consented as we could not retrieve information for participants with, for example, subscriptions registered via an employer or prepaid service. We have so far obtained operator data for $12 \% \quad(n=10394)$ of the cohort for the baseline (2011-2012) period (from one operator). Data for a total of around 21\% ( $\mathrm{n} 18500)$ are being retrieved for subsequent time periods and from additional operators.

\section{Health outcome ascertainment}

Multiple health outcomes were ascertained in the baseline questionnaires, incidence is monitored through regular linkage to registries and changes in self-reported health are being assessed in follow-up questionnaires. Linkage to the registries was based on personal identifying information. Information on vital status was obtained from the Municipal Personal Records Database, and information on cause of death was obtained from the national mortality registry (Statistics Netherlands) in $2015-2017 .^{38}$ Data on cancer incidence were obtained from the Netherlands Cancer Registry; data are available from 1989 onwards and the most recent linkage was in $2017 .{ }^{39}$ Most participants in AMIGO and EPIC-NL (33\% of LIFEWORK) gave consent to retrieve health outcome information from their general practitioner. In AMIGO, information was obtained from the NIVEL Primary Care Database, which comprises electronic health record data from primary care physicians on consultations, drug prescriptions and referrals from 2005 onwards. ${ }^{41}$ Linkage to cause-of-death and cancer health registries will occur on a (bi)annual basis, and linkage to other registries (eg, the Hospital Discharge Registry) will be performed periodically, depending on research projects.

Health outcomes which are not easily captured by registries were assessed using validated questionnaires, such as headache (Headache Impact Test-6), identification of migraine (ID-migraine), sleep quality (Medical Outcomes Study), general well-being (Short Form-12) and respiratory symptoms (based on the European Community Respiratory Health Survey). ${ }^{16-19} 4243$ As part of the individual study protocols, biological materials were gathered for a subset of the participants. Blood samples were collected for the majority of the EPIC-NL participants (in 1993-1997). ${ }^{11}$ In the Nightingale Study, toenail clippings were collected ( $\mathrm{n}=23439$ ) on which DNA and other analyses can be performed. ${ }^{13}$

\section{Statistical analyses}

We assessed the repeatability of several questionnaire items related to exposure assessment and a primary exposure of interest, mobile phone use, along with several characteristics we expected to remain stable (eg, country of origin, height). The repeatability was assessed by per cent observed agreement and reliability: weighted Cohen's kappa statistic for categorical data (equal $\kappa_{\mathrm{w}}$ for nominal data and squared $\kappa_{\mathrm{w}}$ for ordinal data) or intraclass correlation coefficient for continuous data. We performed a stratified analysis on those who completed two questionnaires 1-4 months versus more than 5 months apart, which approximates the median time (151 days) between completing the two questionnaires; we excluded men and those who had completed the questionnaire within a period of less than 1 month $(\mathrm{n}=28)$. Minimal relative risks (RR) detectable with $80 \%$ power were estimated for the end of 2016 and 2021 by a logistic generalised additive model for different exposure prevalences (5\%-50\%) for three diseases with varying age-standardised incidence and mortality rates. Information on the size, age and sex distribution of LIFEWORK was combined with outcome-specific incidence or mortality rates for the Netherlands. ${ }^{38}$ Statistical analyses were performed using R, V.3.2.2 (R Foundation for Statistical Computing, Vienna, Austria). Geospatial modelling was performed using ArcGIS 10.3 (ESRI, Redlands, CA, USA).

\section{FINDINGS TO DATE \\ Baseline characteristics}

Baseline characteristics of the LIFEWORK cohort are shown in table 2. A large proportion of the cohort is female $(\mathrm{n}=79$ 162, 90\% female; $\mathrm{n}=9304,10 \%$ male), as only women were recruited for the Nightingale Study and one of the two EPIC-NL cohorts (Prospect). ${ }^{11}$ At LIFEWORK baseline (2011-2012), the median age was 51 years, and $43 \%$ were between 50 and 64 years of age. Three-quarters of participants were employed. Nearly half were overweight or obese, and more than half had ever smoked. Seventy-two per cent of participants reported ever having used a mobile phone. Over a third $(36 \%)$ reported to call $>30 \mathrm{~min} /$ week in the 3 months prior to baseline. Twenty-two per cent (or $36 \%$ of the participants who had ever used a mobile phone) had used a mobile phone for more than 10 years by 2012. Participants resided in all areas of the Netherlands (see figure 1), although some clustering can be identified (such as in the central province of Utrecht, where EPIC-NL recruitment was concentrated), and slightly more participants lived in rural areas than urban areas.

\section{Environmental exposure distributions}

Exposure distributions for a selected set of residential environmental exposures are shown in table 3 . The median exposure level was $22.9 \mu \mathrm{g} / \mathrm{m}^{3}$ for $\mathrm{NO}_{2}, 16.6 \mu \mathrm{g} / \mathrm{m}^{3}$ for $\mathrm{PM}_{2.5}, 53.1 \mathrm{~dB}$ for noise and $0.003 \mathrm{mWm}^{2^{2}}$ for RF-EMF from mobile phone base stations. Contrast (range/mean) for $\mathrm{PM}_{2.5}$ and $\mathrm{NO}_{2}$ was $39 \%$ and $339 \%$, respectively. Spearman correlation coefficients between the environmental exposures ranged from 0.14 to 0.86 (online supplementary figure S1). The highest correlations were found between several air pollutants $\left(0.86\right.$ for $\mathrm{PM}_{2.5}$ absorbance and $\left.\mathrm{PM}_{10}\right)$ and negative correlations ranging from -0.20 to -0.54 were observed between greenness (NDVI) and all other environmental exposures. 
Open Access

Table 2 Baseline characteristics of the LIFEWORK participants ( $n=88$ 466, 2011-2012)

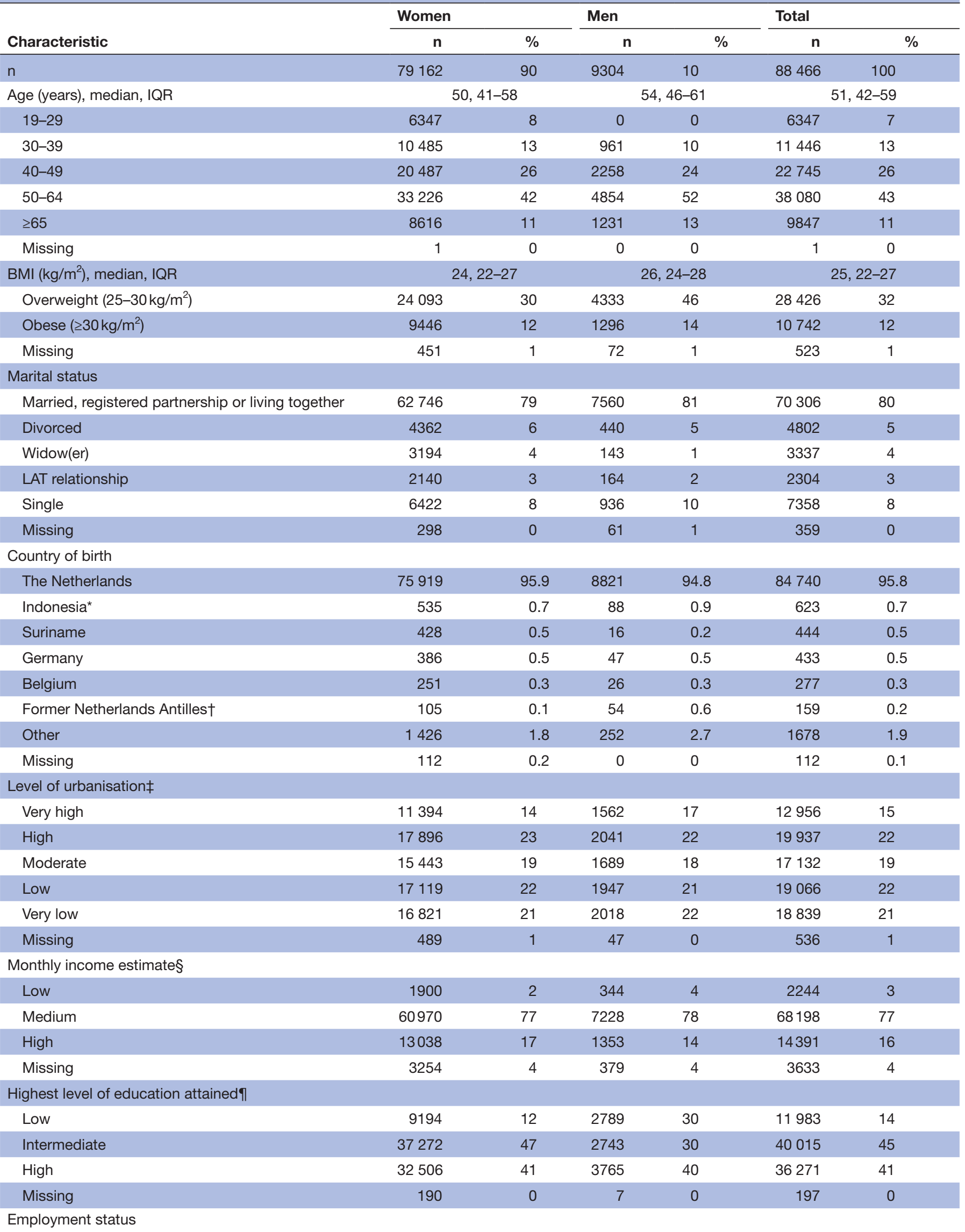


Table 2 Continued

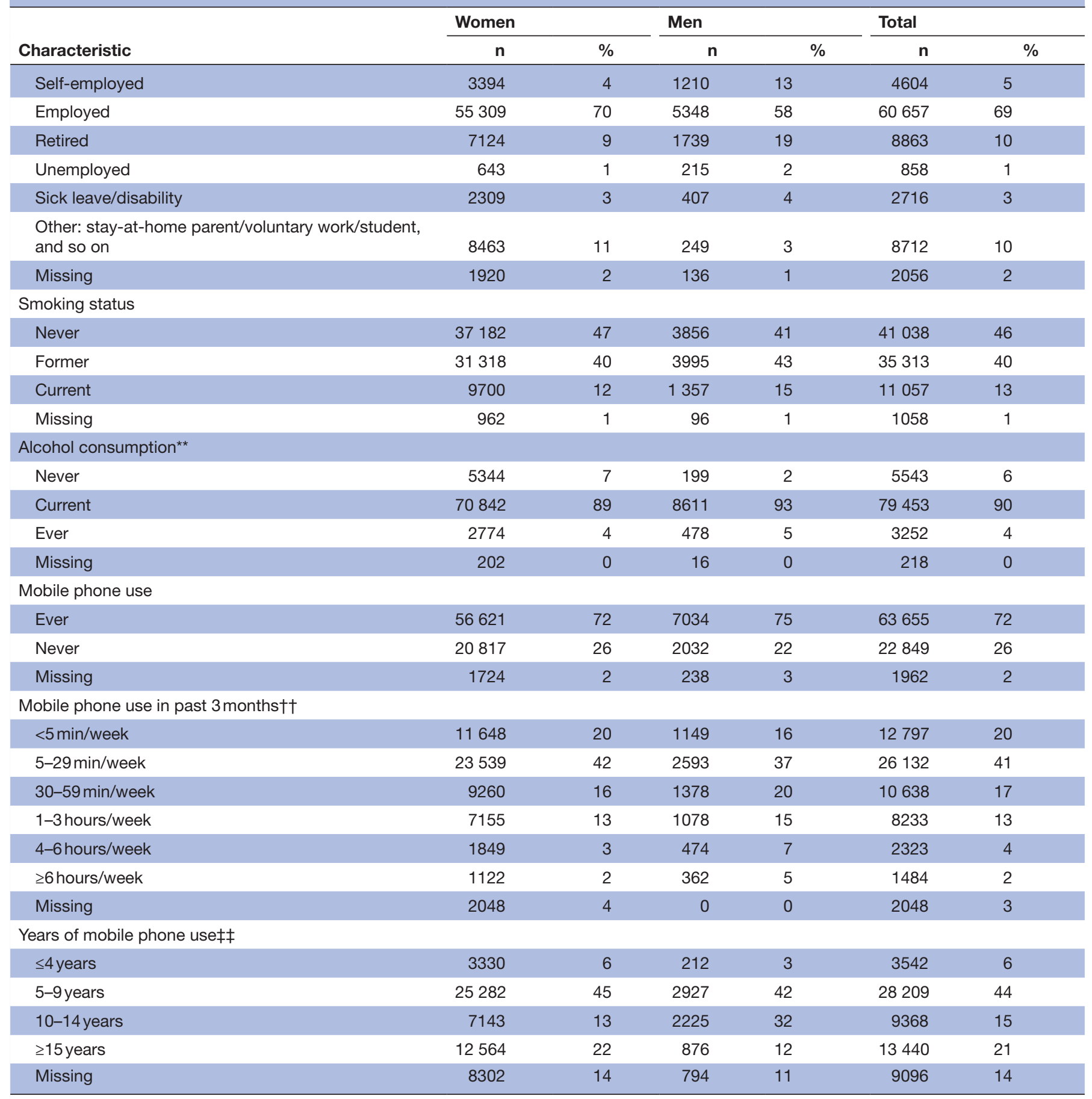

*Indonesia including former Dutch East Indies.

†Aruba, Bonaire, Curacao, St Martin, St Eustatius.

$\ddagger$ Average number of addresses $/ \mathrm{km}^{2}$ on postal code level within a radius of $1 \mathrm{~km}$ of the home address at LIFEWORK baseline; categorised into five levels ranging from very high=on average $>2500$ addresses $/ \mathrm{km}^{2}$; high=on average $1500-2500$ addresses $/ \mathrm{km}^{2} ;$ moderate=on average $1000-1500$ addresses $\mathrm{km}^{2}$; low=on average $500-1000$ addresses $/ \mathrm{km}^{2}$; and very low =on average $<500$ addresses $/ \mathrm{km}^{2}{ }^{38}$

$\S$ Household income was estimated based on participants' baseline postal code. Each postal code was linked to income data from Statistics Netherlands for December 2008; the cut-off values for low income and high income were respectively the 40th and 80th percentiles in income. ${ }^{38}$

ILow: primary school, lower vocational training or lower secondary education; intermediate: intermediate vocational education or intermediate/higher secondary education; high: higher vocational education or university degree.

${ }^{\star *}$ Current: more than one glass per week in the past 12 months; ever: less than one glass per week in the past 12 months.

††Calculated among the participants who reported using a mobile phone in the 3 months prior to baseline $(n=57644)$.

$\ddagger \ddagger$ Calculated among the participants who reported having ever used a mobile phone $(n=63$ 655) for the year 2012.

BMI, body mass index; LAT, living-apart-together. 


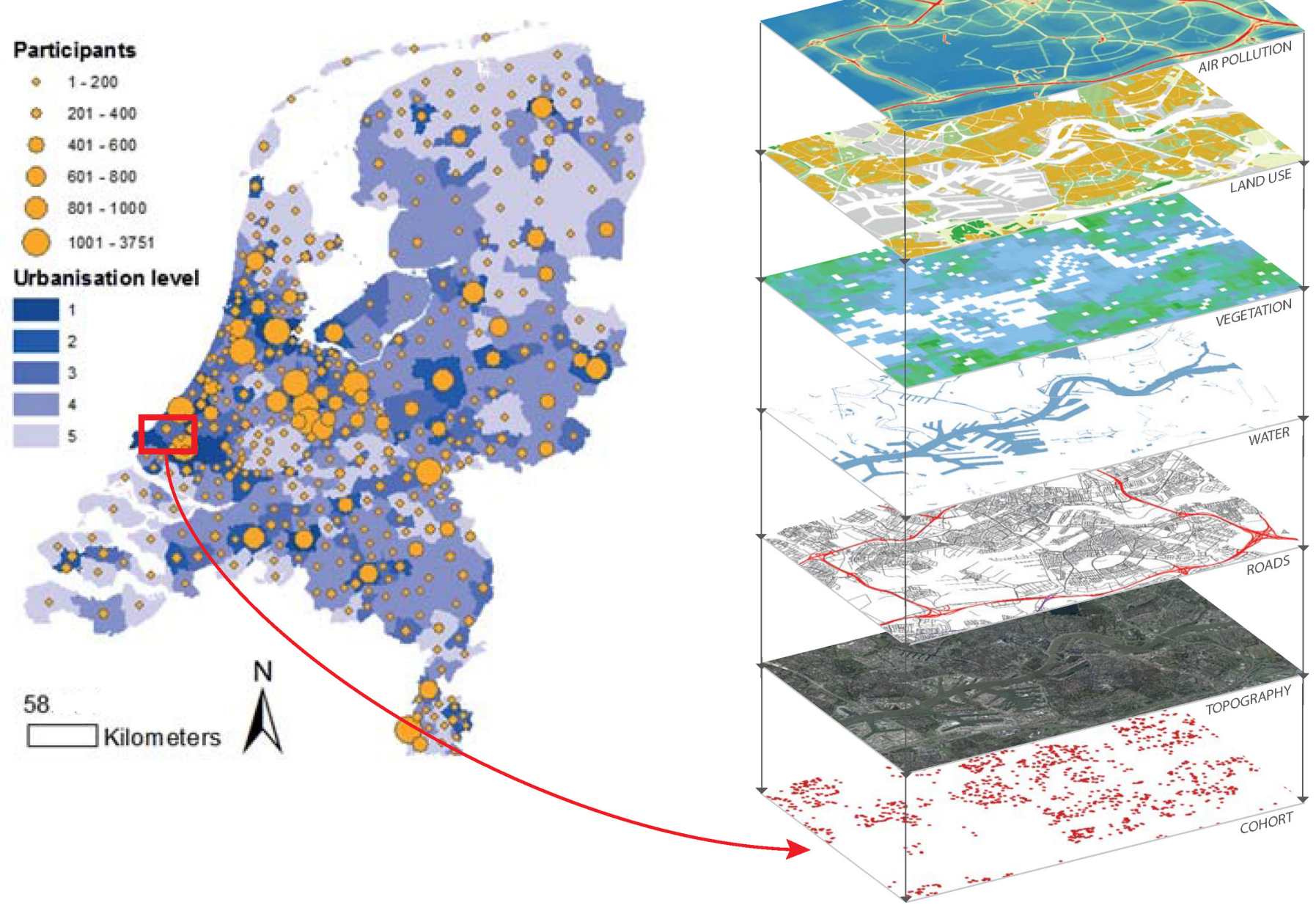

Figure 1 Distribution of LIFEWORK participants (circles) and urbanisation level per municipality across the Netherlands. Five urbanisation levels ranging from 1 (low, $<500$ addresses $/ \mathrm{km}^{2}$ ) to 5 (very high, $\geq 2500$ addresses $/ \mathrm{km}^{2}$ ). Overlay of environmental layers in the Rotterdam area respectively from bottom to top: location of participants, topography, roads, water, greenness (Normalized Difference Vegetation Index), land use and air pollution.

\section{Occupational exposures}

The LIFEWORK baseline prevalence of selected occupational exposures is shown in figure 2 for sources of occupational-related EMF exposures (in the entire cohort, $n=88466$ ), occupational exposures based on the DOM-JEM for a subset of the AMIGO general population cohort $(\mathrm{n}=4961)$ and for nurse-specific occupational exposures (Nightingale, $n=59$ 941). The most common sources of recent occupational-EMF exposure were working in the vicinity of MRI equipment $(7 \%)$ and using dielectric heating $(3 \%)$. In the subset for whom occupational histories were linked to DOM-JEM, lifetime exposures were highest $(25 \%)$ for organic dust (a mixture of dust from organic substances such as wood, flour, and so on) and endotoxin (16\%). The majority of the Nightingale Study participants reported to have ever worked with antibiotics $(75 \%)$, and around a quarter $(23 \%-27 \%)$ with antineoplastic drugs, routine X-rays or ultrasound equipment. A large proportion of LIFEWORK participants, $66 \%$, reported to have ever conducted shift work; $80 \%$ of Nightingale and $32 \%$ of the two general population cohorts (AMIGO and EPIC-NL).

\section{Repeatability of questionnaire items}

For the 265 participants who completed the LIFEWORK questionnaire twice, the median interval between completing the two questionnaires was 151 days (IQR: 122-186). These participants had a mean age of 51 years (IQR 30-66) and 98\% were female. The repeatability of several exposures and covariates is presented in table 4 . Repeatability of country of origin and height was excellent $\left(\kappa_{w} \geq 0.97\right)$. Questions on recent mobile phone use (duration) had a moderately good repeatability $\left(\kappa_{w}=0.73\right)$. For historical use (duration), the weighted kappa was poor to moderate at $0.04,0.21,0.70,0.69$ and 0.55 , respectively, for 1990, 1995, 2000, 2005 and 2010 (online supplementary table S2). In stratified analyses, no clear differences were observed for participants who filled in the questionnaires between 1 and 4 months versus more than 5 months apart. 
Table 3 Exposure distributions for environmental exposures at the baseline home addresses based on geospatial modelling (LIFEWORK, $n=88$ 466, 2011-2012)

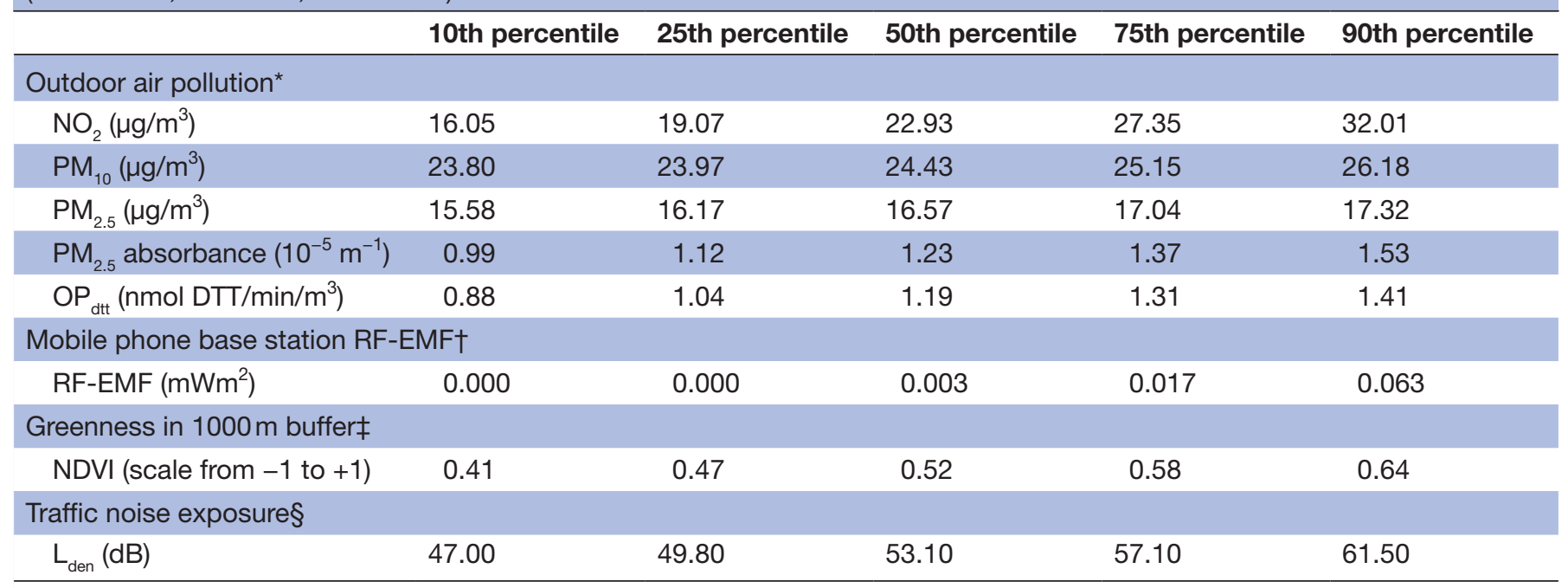

${ }^{*}$ ESCAPE LUR model based on data from 2008 to 2011.

†NISMap estimates with antenna data from 2011.

‡NDVI in 2011.

§STAMINA traffic data from 2011.

DTT, dithiothreitol; ESCAPE, European Study of Cohorts for Air Pollution Effects; $\mathrm{L}_{\text {den }}$, day-evening-night weighted average traffic noise level; LUR, land use regression; NDVI, Normalized Difference Vegetation Index; $\mathrm{NO}_{2}$, nitrogen dioxide; $\mathrm{OP}_{\text {dtt }}$, oxidative potential measured by dithiothreitol; $\mathrm{PM}_{2.5}$, particulate matter with diameter $\leq 2.5 \mu \mathrm{m} ; \mathrm{PM}_{10}$, particulate matter with diameter $\leq 10 \mu \mathrm{m}$; RF-EMF, radiofrequency electromagnetic fields; STAMINA, Standard Model Instrumentation for Noise Assessments.

\section{Power calculations}

Minimal detectable for the different exposure scenarios (5\%-50\% exposure prevalence) and years (2021 and
2016) RRs ranged from 1.12 to 1.28 for stroke (age-standardised mortality: $0.700 / 1000), 1.36$ to 2.36 for Parkinson's disease (age-standardised incidence: 0.074/1000)

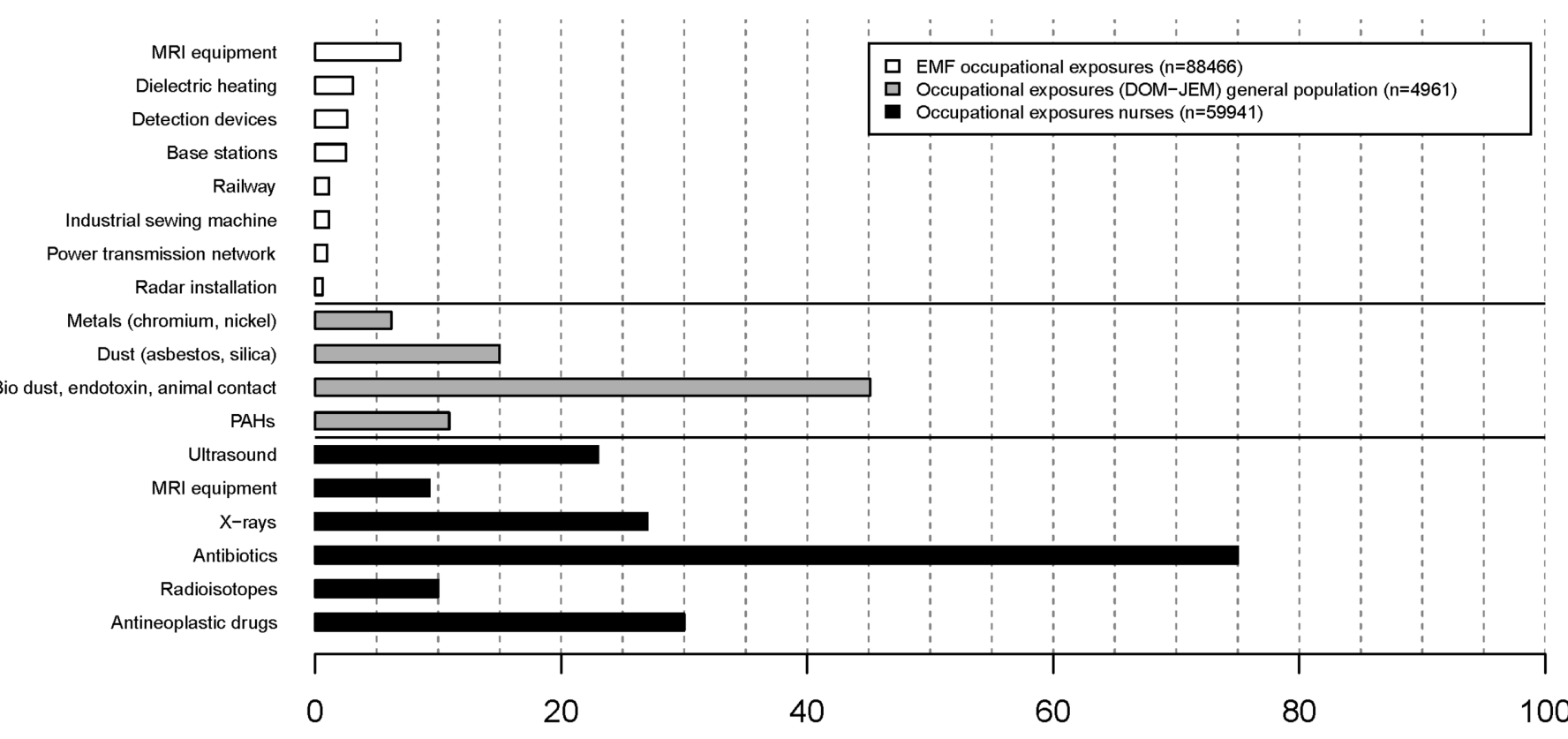

\section{Percentage}

Figure 2 Frequency of selected lifetime occupational exposures based on self-reports or estimated from job-exposure matrices. These are stratified by exposures to occupational sources of high electromagnetic fields at baseline $(n=88466$, ie, all LIFEWORK participants); lifetime exposure to occupational chemicals (DOM-JEM ${ }^{34}{ }^{35}$ ) in the subset with coded job titles ( $n=4961$ in AMIGO, the Occupational and Environmental Health Cohort Study); and lifetime exposure for at least 6 months to occupational agents in the subcohort of nurses ( $n=59$ 941, the Nightingale Study). EMF, electromagnetic field; JEM, jobexposure matrix; PAH, polycyclic aromatic hydrocarbon. 
Table 4 Test-retest repeatability* for selected key items in the LIFEWORK baseline questionnaire

\section{Overall $\quad 1-4$ months $\geq 5$ months}

\begin{tabular}{|c|c|c|c|c|c|c|c|c|c|}
\hline Variable & $\mathbf{n}$ & $\begin{array}{l}\text { Per cent } \\
\text { agreement }\end{array}$ & $\begin{array}{l}\text { Reliability } \\
\text { ( } \kappa_{w} \text { or } \\
\text { ICC) }\end{array}$ & $\mathbf{n}$ & $\begin{array}{l}\text { Per cent } \\
\text { agreement }\end{array}$ & $\begin{array}{l}\text { Reliability } \\
\text { ( } \kappa_{\mathrm{w}} \text { or } \\
\text { ICC) }\end{array}$ & $\mathbf{n}$ & $\begin{array}{l}\text { Per cent } \\
\text { agreement }\end{array}$ & $\begin{array}{l}\text { Reliability } \\
\text { ( } \kappa_{w} \text { or } \\
\text { ICC) }\end{array}$ \\
\hline \multicolumn{10}{|l|}{ General } \\
\hline Country of origin & 237 & 100 & 1 & 83 & 100 & 1 & 154 & 100 & 1 \\
\hline Height $(\mathrm{cm}) \dagger$ & 237 & 61.6 & 0.97 & 83 & 67.5 & 0.99 & 154 & 58.4 & 0.97 \\
\hline $\begin{array}{l}\text { Since when at current } \\
\text { address (year) } \neq\end{array}$ & 236 & 78.6 & 0.98 & 82 & 84.5 & 0.99 & 154 & 74.7 & 0.97 \\
\hline Floor of bedroom‡ & 231 & 87.4 & 0.90 & 81 & 87.7 & 0.72 & 150 & 87.3 & 0.92 \\
\hline Bedroom window glazing $\ddagger$ & 233 & 95.3 & 0.84 & 81 & 98.8 & 0.96 & 152 & 93.4 & 0.75 \\
\hline \multicolumn{10}{|l|}{ Mobile phone use§ } \\
\hline $\begin{array}{l}\text { Past } 3 \text { months: mobile } \\
\text { phone use (duration, } \\
\text { categorical) }\end{array}$ & 107 & 57.9 & 0.73 & 32 & 56.2 & 0.62 & 75 & 58.7 & 0.76 \\
\hline $\begin{array}{l}\text { Mobile phone use in } 2005 \\
\text { (duration, categorical) }\end{array}$ & 107 & 59.8 & 0.69 & 32 & 65.6 & 0.65 & 75 & 57.3 & 0.70 \\
\hline $\begin{array}{l}\text { Mobile phone use in } 2000 \\
\text { (duration, categorical) }\end{array}$ & 107 & 57.0 & 0.70 & 32 & 50.0 & 0.52 & 75 & 60.0 & 0.75 \\
\hline $\begin{array}{l}\text { Laterality (held on left, } \\
\text { right, equal) }\end{array}$ & 138 & 78.3 & 0.69 & 38 & 84.2 & 0.76 & 100 & 76.0 & 0.66 \\
\hline
\end{tabular}

*Excluding men $(n=1)$ and participants filling in the questionnaire within 1 month $(n=27)$.

†Height for the EPIC-NL subcohort is based on baseline in EPIC-NL which was in 1993-1997.

†Excluding the participant who moved in the period between completing the LIFEWORK baseline questionnaire twice $(\mathrm{n}=1)$.

$\S$ Only calculated among participants who reported to use a mobile phone at baseline (percentage agreement $=82.1, n=235$ ).

EPIC-NL, European Prospective Investigation into Cancer and Nutrition in the Netherlands; ICC, intraclass correlation coefficient.

and 1.64 to 3.60 for brain cancer (age-standardised mortality: 0.006/1000) (online supplementary figure S2). Self-reported doctor diagnosis of conditions and disease prevalence at baseline is shown in online supplementary table S3, and was the highest for high blood pressure, cholesterol, migraine and asthma $(18.8 \%-6.5 \%)$.

\section{STRENGTHS AND LIMITATIONS}

Through an efficient approach of collecting data in three different cohort studies, we established the LIFEWORK cohort, the largest contemporary Dutch prospective cohort study on occupational and environmental risks with a nationwide distribution in the Netherlands. The detail and wealth of the data collected on a broad array of occupational and environmental exposures is illustrated in this paper. The data enable assessments of health effects of single exposures, and of more complex epidemiological analyses on multiple simultaneous and timevarying exposures, such as the combined effects of EMF, green space, air pollution, traffic noise and work-related exposures. In addition to extensive exposure data, information on a large set of potential confounders and effect modifiers, and self-reported and registry-recorded acute and chronic health outcomes is available.

The design of LIFEWORK was efficient but influenced the composition of the cohort; for example, the majority of the cohort is female $(90 \%)$, over the age of 50 years
(54\%), and nursing is the most common occupation. There will be greater statistical power to study associations with female-specific health outcomes, such as breast cancer and diseases which are more prevalent in women, such as certain autoimmune diseases and mental disorders (eg, major depression).$^{44}$ There should be sufficient statistical power to study effect modification by sex for many exposure-outcome associations, but likely not for some rarer exposures or outcomes. Furthermore, exposures associated with the nursing profession will be more prevalent in the study population compared with the general working population. The participants are higher educated than the general population because nurses, who account for more than $60 \%$ of the study population, have at least an intermediate level of education. ${ }^{38}$ Other consequences of the recruitment strategies are clustering of participants in the centre of the country (in and around Utrecht), and that the proportion of participants employed at baseline is high $(74 \%$ vs $71 \%$ for the adult population of the Netherlands), ${ }^{38}$ which implies high statistical power for investigating occupational risks, especially for exposures related to nursing.

That LIFEWORK is not fully representative of the Dutch adult population with respect to sex, age and occupation, does not hamper the ability to detect and estimate exposure-outcome associations and for valid inferences, assuming adequate control of confounding variables. ${ }^{45}$ 
We have collected data on a diverse set of potential confounding variables and endeavoured to minimise their measurement error. A limitation, common to many observational prospective cohorts, is selection bias, particularly due to attrition. This will be minimised by using health registries to assess health outcomes, and may, in case of usage of questionnaire data, also be accounted for using modelling approaches to account for selection effects and time-varying confounding. ${ }^{46-48}$ Due to the prospective assessment of health outcomes, possible misclassification of exposures based on retrospective assessment of lifetime occupational, residential and mobile phone histories is expected to be largely non-differential. Healthy worker survivor effect is a concern in occupational cohorts; however, for the Nightingale Study, participants were recruited from the healthcare professional registration system and working in the field was not a prerequisite for inclusion. Both AMIGO and EPIC-NL recruited from the (working age) general population, for which healthy worker effect is less of a problem.

Two of the three subcohorts were invited to complete a web-based questionnaire, and one subcohort (EPIC-NL, $16 \%$ ) with an older age distribution was invited to complete a paper questionnaire which was the customary approach in that study. An advantage of the web-based questionnaire was that more participants could be invited due to the lower cost of printing and data entry. ${ }^{49}$ This might have led to an over-representation of more computer-proficient individuals (generally more educated and younger); however, we expect this selection to have been minimal as internet access in the Netherlands is very high $(>97 \%),{ }^{50}$ and no difference in response rates was observed in a recent study of older patients in the Netherlands which offered web-based questionnaires (with paper optional) and paper-based questionnaire ${ }^{51}$ Minor differences in the completion rates and data quality can be expected for the web-based versus paper questionnaires, for example, because error messages appeared in the web-based versions when sections were incomplete or highly unlikely values were entered. Further, web-based questionnaires may be less prone to social desirability bias. $^{52}$

LIFEWORK is the second largest contributor to the COSMOS study, comprising nearly 90000 of the 290000 participants enrolled to date. ${ }^{14}$ Mobile phone use was somewhat lower in LIFEWORK compared with the study populations from the other countries in COSMOS, especially the proportion who frequently called with a mobile phone ( $>30 \mathrm{~min} /$ week). Explanations for this are likely the older age distribution of LIFEWORK compared with the other countries' cohorts, and that the other COSMOS countries oversampled, based on operator records, heavy mobile phone users, and excluded those not using mobile phones (which constituted 26\% of LIFEWORK participants). A strength of COSMOS is that in addition to gathering questionnaire data on mobile phone use, objective data are collected from operators, allowing for application of measurement error models (eg, regression calibration).
Another strength is the prospective cohort design, which reduces possible recall bias and selection bias. This was a possible limitation of previous case-control studies on mobile phone use and health. ${ }^{53}$ Compared with the large INTERPHONE study on mobile phone use and brain tumours, participants of LIFEWORK (and cohorts comprising the COSMOS consortium) have a longer time since first use and a higher proportion are heavy users. ${ }^{54}$ Twenty-six per cent of LIFEWORK participants reported using a mobile phone $>30 \mathrm{~min} /$ week at baseline and the average time since first usage was 11 years (IQR 8-14 years), which is higher than the highest category in the INTERPHONE study ( $\geq 10$ years). ${ }^{54}$ This will be informative to address current scientific uncertainties regarding the possible health effects of long term and heavy mobile phone usage, although cumulative RF-EMF exposures will in part be compensated by the fact that modern phones produce less RF-EMF due to adaptive power control and network evolution (eg, $2 \mathrm{G}$ to $3 \mathrm{G}$ ). ${ }^{2}$ The detailed information on the use of mobile communication devices also allows for research on borderless working and (blue) light-at-night exposure, exposures of emerging concern.

Because 265 participants completed the baseline LIFEWORK questionnaire twice, we assessed the repeatability of certain questionnaire items, such as questions related to mobile phone use, which is one of the key research areas of interest. The repeatability of questions on recent mobile phone use was substantial. The low kappa for 1990 and 1995 for mobile phone usage (duration) was probably due to the low overall usage in these years; however, the percentage agreement for these periods was high $(90 \%$ and $79 \%)$. Stratified analysis showed that the time between the two questionnaires (more or less than 5 months) did not result in consistently different repeatability coefficients. Variables answered with substantial repeatability, such as mobile phone usage, will increase statistical power, while variables with moderate agreement, such as bedroom floor (important for modelling some environmental exposures), will have greater measurement error and consequently reduced statistical power.

A large amount of data has been collected for nearly 90000 participants in LIFEWORK. The large sample size, widespread geographic coverage of participants across the Netherlands and the large contrast in levels of occupational and environmental exposures will allow us to study both common diseases and relatively rare diseases, such as Parkinson's disease, as shown by the power analysis. This wealth of data creates opportunities but will also lead to analytical challenges, such as disentangling the effects of duration and rate of exposure histories, and the independent effects of multiple, potentially correlated exposures. ${ }^{55-57}$ Pooling resources to create the LIFEWORK cohort enabled us to design a larger cohort with a broad array of exposures and outcomes; however, there are challenges to such a federated structure. Reaching consensus on core questionnaire topics can be resource intensive, although we do benefit from diverse expertise. 
Furthermore, coordinating follow-up of the cohort is a challenge, and ultimately there will likely be some time gaps between some of the questionnaire campaigns across the subcohorts and potentially unequal coverage of registry linkage.

\section{Future plans}

We are now in the phase of actively and passively observing participants. Data collection for the first follow-up questionnaire was completed for two of the three subcohorts in 2015 and will be completed for the third subcohort in 2018. Linkage to cause-of-death and cancer registries has been performed for all subcohorts as of 2017 . We plan to administer questionnaires every $4-5$ years, and aim to continue this for $20+$ years, depending on future funding. As we have the email addresses of $\sim 80 \%$ of the cohort, it would be possible to contact a subset of the cohort in a cost-efficient manner. Using web-based invitations and questionnaires would eliminate printing and mailing costs, and reduce data management costs; nonetheless, costs associated with modifying the online questionnaire and providing support to participants can still be substantial. We could target specific groups (eg, higher exposed participants), or send dedicated in-depth questions based on their answers in earlier questionnaires. We are also piloting the use of smartphone applications to passively monitor exposures-presently mobile phone usage, with plans to extend this to ecological momentary assessments of time activity, and food frequency surveys-and are exploring using wearable passive samplers to assess exposures and physical activity in a subset of participants. ${ }^{559}$

\section{Collaboration}

The LIFEWORK prospective cohort will continue to collect a rich set of data on multiple exposure domains and health outcomes. For more information, refer to the web site: lifeworkstudy.nl. Researchers interested in collaboration are invited to propose occupational and environmental research based on the data available within LIFEWORK or to submit a request for additional data collection. Requests can be submitted to RCHV (r. c.h.vermeulen@uu.nl) and will be reviewed by the LIFEWORK scientific board. LIFEWORK has an overarching governance board, and each subcohort has an independent and partially overlapping governance board. It is also possible to seek independent collaboration with one of the subcohorts (refer to http://www.amigoproject.nl/ contact/, https://www.epicnl.eu/Home/EPICNL and http://www.nightingalestudie.nl/Pages/for-researchers/ for contact information).

\footnotetext{
Author affiliations

${ }^{1}$ Division of Environmental Epidemiology, Institute for Risk Assessment Sciences, Utrecht University, Utrecht, The Netherlands

${ }^{2}$ Department of Epidemiology, Julius Center for Health Sciences and Primary Care, University Medical Center Utrecht, Utrecht, The Netherlands

${ }^{3}$ Department of General Practice and Elderly Care Medicine, Amsterdam Public Health Research Institute, VU University Medical Center, Utrecht, The Netherlands ${ }^{4}$ Netherlands Cancer Institute, Antoni van Leeuwenhoek Hospital, Amsterdam, The Netherlands
}

${ }^{5}$ Department of Biostatistics and Epidemiology, Imperial College London, London, UK ${ }^{6}$ Netherlands Institute for Health Services Research (NIVEL), Utrecht, The Netherlands

${ }^{7}$ National Institute for Public Health and the Environment (RIVM), Bilthoven, The Netherlands

Acknowledgements The authors thank Eef van Otterloo from Utrecht University, Susan van Hemert from the University Medical Center Utrecht and Jan van der Laan from the Dutch National Institute for Public Health and the Environment (RIVM) for helping with the data collection, online applications, technical support and data management tasks. They also are grateful to Joris IJzermans (NIVEL) and the general practitioners for their contribution to the establishment of AMIGO. The authors also thank Jeroen van Leuken, Danny Houthuijs and Wim Swart from the Dutch RIVM and Maciej Strak from Utrecht University for their help in providing and modelling the greenness, noise and air pollution estimates. They also thank Lützen Portengen from Utrecht University for the power analysis simulation, Anke Hüss and Susan Peters from Utrecht University for their contributions to the development of several job exposure matrices, and Mattijs Numans of the Utrecht Health Project (Leidsche Rijn Gezondheids Project) for his contribution to the study in the initial phase.

Contributors MR, VL and RCHV conceived the present analysis and manuscript. MR contributed to data collection, performed the data analysis and drafted the manuscript, with contributions from VL. PS, AP, PHP, BBdM, WMMV, FEvL, MAR, HK and RCHV designed and established the LIFEWORK cohort and the contributing subcohorts (PS and RCHV: AMIGO; BBdM, WMMV and PHP: EPIC-NL; AP, RCHV, FEvL and MAR: Nightingale), and are also responsible for their continued management (as previous, except JCK, RAV and RCHV: AMIGO). HK and RCHV obtained funding for the LIFEWORK cohort. IP was responsible for data management. All authors reviewed, critically revised and approved the manuscript.

Funding This research was funded by the Netherlands Organisation for Health Research and Development (ZonMw) within the Electromagnetic Fields and Health Research programme (grant numbers 85200001 and 85500003 ), the National Institute for Public Health and the Environment (RIVM) and the Netherlands Cancer Institute. The EPIC-NL study was funded by 'Europe against Cancer' Programme of the European Commission (DG SANCO); the Dutch Ministry of Health, Welfare and Sports (VWS); the ZonMw; and the World Cancer Research Fund (WCRF). ESCAPE received funding from the European Community's Seventh Framework Program (FP7/2007-2011) under grant agreement number 211250.

Competing interests None declared.

Patient consent Obtained.

Ethics approval The contributing subcohorts were approved by the local research ethics review committee or institutional review board (AMIGO and EPIC-NL Prospect by the committee at the University Medical Center Utrecht; EPIC-NL MORGEN by the committee at TNO Nutrition and Food Research; and Nightingale by the committee at the Netherlands Cancer Institute), and participants signed an informed consent form for each subcohort prior to enrolment.

Provenance and peer review Not commissioned; externally peer reviewed.

Data sharing statement Available data are listed in online supplementary table S1. Researchers interested in collaboration are invited to propose occupational and environmental research based on the data available within LIFEWORK or to submit a request for additional data collection. Requests can be submitted to RCHV (r.c.h. vermeulen@uu.nl) and will be reviewed by the LIFEWORK scientific board.

Open Access This is an Open Access article distributed in accordance with the Creative Commons Attribution Non Commercial (CC BY-NC 4.0) license, which permits others to distribute, remix, adapt, build upon this work non-commercially, and license their derivative works on different terms, provided the original work is properly cited and the use is non-commercial. See: http://creativecommons.org/ licenses/by-nc/4.0/

(C) Article author(s) (or their employer(s) unless otherwise stated in the text of the article) 2018. All rights reserved. No commercial use is permitted unless otherwise expressly granted.

\section{REFERENCES}

1. Newby DE, Mannucci PM, Tell GS, et al. Expert position paper on air pollution and cardiovascular disease. Eur Heart $J$ 2015;36:83-93. 
2. IARC Working Group on the Evaluation of Carcinogenic Risks to Humans. Non-ionizing radiation, Part 2: Radiofrequency electromagnetic fields. IARC Monogr Eval Carcinog Risks Hum 2013:102:1-460.

3. Pekkanen J, Pearce N. Environmental epidemiology: challenges and opportunities. Environ Health Perspect 2001;109:1-5.

4. Patel CJ. Analytic complexity and challenges in identifying mixtures of exposures associated with phenotypes in the exposome era. Curr Epidemiol Rep 2017;4:22-30.

5. Rappaport SM. Implications of the exposome for exposure science. $J$ Expo Sci Environ Epidemiol 2011;21:5-9.

6. Wild CP. The exposome: from concept to utility. Int J Epidemiol 2012;41:24-32.

7. Forouzanfar $\mathrm{MH}$, Alexander $\mathrm{L}$, Anderson $\mathrm{HR}$, et al. Global, regional, and national comparative risk assessment of 79 behavioural, environmental and occupational, and metabolic risks or clusters of risks in 188 countries, 1990-2013: a systematic analysis for the Global Burden of Disease Study 2013. Lancet 2015;386:2287-323.

8. Rappaport SM. Discovering environmental causes of disease. $J$ Epidemiol Community Health 2012;66:99-102.

9. Lim SS, Vos T, Flaxman AD, et al. A comparative risk assessment of burden of disease and injury attributable to 67 risk factors and risk factor clusters in 21 regions, 1990-2010: a systematic analysis for the Global Burden of Disease Study 2010. Lancet 2012;380:2224-60.

10. Goldberg M, Carton M, Descatha A, et al. CONSTANCES: a general prospective population-based cohort for occupational and environmental epidemiology: cohort profile. Occup Environ Med 2017;74:66-71.

11. Beulens JW, Monninkhof EM, Verschuren WM, et al. Cohort profile: the EPIC-NL study. Int J Epidemiol 2010;39:1170-8.

12. Slottje P, Yzermans CJ, Korevaar JC, et al. The population-based occupational and environmental health prospective cohort study (amigo) in The Netherlands. BMJ Open 2014;4:e005858.

13. Pijpe A, Slottje $P$, van Pelt $C$, et al. The Nightingale study: rationale, study design and baseline characteristics of a prospective cohort study on shift work and breast cancer risk among nurses. BMC Cancer 2014;14:47.

14. Schüz J, Elliott $P$, Auvinen $A$, et al. An international prospective cohort study of mobile phone users and health (Cosmos): design considerations and enrolment. Cancer Epidemiol 2011;35:37-43.

15. Toledano MB, Auvinen A, Tettamanti G, et al. An international prospective cohort study of mobile phone users and health (COSMOS): factors affecting validity of self-reported mobile phone use. Int J Hyg Environ Health 2018;221:1-8.

16. Kosinski M, Bayliss MS, Bjorner JB, et al. A six-item short-form survey for measuring headache impact: the HIT-6. Qual Life Res 2003;12:963-74.

17. Lipton RB, Dodick D, Sadovsky R, et al. A self-administered screener for migraine in primary care. Neurology 2003;61:375-82.

18. Hays RD, Martin SA, Sesti AM, et al. Psychometric properties of the medical outcomes study sleep measure. Sleep Med 2005;6:41-4.

19. Burney PG, Luczynska C, Chinn S, et al. The European community respiratory health survey. Eur Respir J 1994;7:954-60.

20. Ware J, Kosinski M, Keller SD. A 12-Item Short-Form Health Survey: construction of scales and preliminary tests of reliability and validity. Med Care 1996;34:220-33.

21. Martens AL, Slottje P, Timmermans DRM, et al. Modeled and perceived exposure to radiofrequency electromagnetic fields from mobile-phone base stations and the development of symptoms over time in a general population cohort. Am J Epidemiol 2017:186:210-9.

22. Kadaster Netherlands. Kadaster Netherlands. https://www.kadaster. $\mathrm{nl} /$ (accessed 17 Aug 2016).

23. Beekhuizen J, Vermeulen R, Kromhout $\mathrm{H}$, et al. Geospatial modelling of electromagnetic fields from mobile phone base stations. Sci Total Environ 2013;445-446:202-9.

24. Beekhuizen J, Vermeulen R, van Eijsden M, et al. Modelling indoor electromagnetic fields (EMF) from mobile phone base stations for epidemiological studies. Environ Int 2014;67:22-6.

25. Rhew IC, Vander Stoep A, Kearney A, et al. Validation of the normalized difference vegetation index as a measure of neighborhood greenness. Ann Epidemiol 2011;21:946-52.

26. Eeftens M, Beelen R, de Hoogh K, et al. Development of Land Use Regression models for PM(2.5), PM(2.5) absorbance, PM(10) and PM(coarse) in 20 European study areas; results of the ESCAPE project. Environ Sci Technol 2012;46:11195-205

27. Beelen R, Hoek G, Vienneau D, et al. Development of NO2 and NOx land use regression models for estimating air pollution exposure in 36 study areas in Europe - The ESCAPE project. Atmos Environ 2013:72:10-23.
28. Scheurs EM, Jabben J, Verheijen ENG. STAMINA-Model description STAMINA - Model description. Rep.680740003/201. 2010 http:// www.rivm.nl/bibliotheek/rapporten/680740003.pdf

29. Locatus. Locatus. http://locatus.com/nederland (accessed 17 Aug 2016).

30. Jedynska A, Hoek G, Wang M, et al. Development of land use regression models for elemental, organic carbon, $\mathrm{PAH}$, and hopanes/ steranes in 10 ESCAPE/TRANSPHORM European study areas. Environ Sci Technol 2014;48:14435-44.

31. Brouwer M, Koeman T, van den Brandt PA, et al. Occupational exposures and Parkinson's disease mortality in a prospective Dutch cohort. Occup Environ Med 2015;72:448-55.

32. de Vocht F, Zock JP, Kromhout H, et al. Comparison of self-reported occupational exposure with a job exposure matrix in an international community-based study on asthma. Am J Ind Med 2005;47:434-42.

33. Matheson MC, Benke G, Raven J, et al. Biological dust exposure in the workplace is a risk factor for chronic obstructive pulmonary disease. Thorax 2005;60:645-51.

34. Peters S, Vermeulen R, Olsson A, et al. Development of an exposure measurement database on five lung carcinogens (ExpoSYN) for quantitative retrospective occupational exposure assessment. Ann Occup Hyg 2012;56:70-9.

35. Peters S, Vermeulen R, Cassidy A, et al. Comparison of exposure assessment methods for occupational carcinogens in a multi-centre lung cancer case-control study. Occup Environ Med 2011;68:148-53.

36. Huss A, Vermeulen R, Bowman JD, et al. Electric shocks at work in Europe: development of a job exposure matrix. Occup Environ Med 2013;70:261-7.

37. Bowman JD, Touchstone JA, Yost MG. A population-based job exposure matrix for power-frequency magnetic fields. J Occup Environ Hyg 2007:4:715-28.

38. Statistics Netherlands. Statistics Netherlands. www.cbs.nl (accessed 24 Oct 2016)

39. van der Sanden GA, Coebergh JW, Schouten LJ, et al. Cancer incidence in The Netherlands in 1989 and 1990: first results of the nationwide Netherlands cancer registry. Coordinating Committee for Regional Cancer Registries. Eur J Cancer 1995;31A:1822-9.

40. NIVEL. NIVEL Primary Care Database. https://www.nivel.nl/en/ dossier/nivel-primary-care-database (accessed 17 Aug 2016).

41. Schweikardt C, Verheij RA, Donker GA, et al. The historical development of the Dutch Sentinel General Practice Network from a paper-based into a digital primary care monitoring system. J Public Health 2016;24:545-62.

42. Karasek R, Brisson C, Kawakami N, et al. The Job Content Questionnaire (JCQ): an instrument for internationally comparative assessments of psychosocial job characteristics. J Occup Health Psychol 1998;3:322-55.

43. Terluin B, van Marwijk HW, Adèr HJ, et al. The Four-Dimensional Symptom Questionnaire (4DSQ): a validation study of a multidimensional self-report questionnaire to assess distress, depression, anxiety and somatization. BMC Psychiatry 2006;6:34

44. de Graaf R, ten Have M, van Gool C, et al. Prevalence of mental disorders and trends from 1996 to 2009. Results from the Netherlands Mental Health Survey and Incidence Study-2. Soc Psychiatry Psychiatr Epidemiol 2012;47:203-13.

45. Rothman KJ, Gallacher JE, Hatch EE. Why representativeness should be avoided. Int J Epidemiol 2013;42:1012-4.

46. Howe CJ, Cole SR, Lau B, et al. Selection bias due to loss to follow up in cohort studies. Epidemiology 2016;27:91-7.

47. Naimi Al, Richardson DB, Cole SR. Causal inference in occupational epidemiology: accounting for the healthy worker effect by using structural nested models. Am J Epidemiol 2013;178:1681-6.

48. Weisskopf MG, Sparrow D, Hu H, et al. Biased exposurehealth effect estimates from selection in cohort studies: are environmental studies at particular risk? Environ Health Perspect 2015;123:1113-22

49. Toledano MB, Smith RB, Brook JP, et al. How to establish and follow up a large prospective cohort study in the 21 st century--lessons from UK COSMOS. PLoS One 2015;10:e0131521.

50. Statistics Netherlands Statline. ICT gebruik van personen naar persoonskenmerken, 2005-2013. http://statline.cbs.nl/StatWeb/ publication/?DM=SLNL\&PA=71098ned\&D1=33,58\&D2=0\&D3=a\& HDR=G1,T\&STB=G2\&VW=T (accessed 24 Sept 2016)

51. Horevoorts NJ, Vissers PA, Mols F, et al. Response rates for patientreported outcomes using web-based versus paper questionnaires: comparison of two invitational methods in older colorectal cancer patients. J Med Internet Res 2015;17:e111-2.

52. van Gelder MM, Bretveld RW, Roeleveld N. Web-based questionnaires: the future in epidemiology? Am J Epidemiol 2010;172:1292-8. 
53. Vrijheid M, Armstrong BK, Bédard D, et al. Recall bias in the assessment of exposure to mobile phones. J Expo Sci Environ Epidemiol 2009;19:369-81.

54. Cardis E. INTERPHONE Study Group. Brain tumour risk in relation to mobile telephone use: results of the INTERPHONE international case-control study. Int J Epidemiol 2010;39:675-94.

55. Richardson DB, Cole SR, Langholz B. Regression models for the effects of exposure rate and cumulative exposure. Epidemiology 2012;23:892-9.

56. Agier L, Portengen L, Chadeau-Hyam M, et al. A systematic comparison of linear regression-based statistical methods to assess exposome-health associations. Environ Health Perspect 2016;124.

57. Lenters V, Vermeulen R, Portengen L. Performance of variable selection methods for assessing the health effects of correlated exposures in case-control studies. Occup Environ Med 2017:0em ed-2016-104231.

58. O'Connell SG, Kincl LD, Anderson KA. Silicone wristbands as personal passive samplers. Environ Sci Technol 2014;48:3327-35.

59. Goedhart G, Kromhout H, Wiart J, et al. Validating self-reported mobile phone use in adults using a newly developed smartphone application. Occup Environ Med 2015;72:812-8.

60. Roenneberg T, Wirz-Justice A, Merrow M. Life between clocks: daily temporal patterns of human chronotypes. J Biol Rhythms 2003;18:80-90

61. Koeman T, Slottje P, Kromhout $\mathrm{H}$, et al. Occupational exposure to extremely low-frequency magnetic fields and cardiovascular disease mortality in a prospective cohort study. Occup Environ Med 2013;70(6):402-7. 